\title{
PK-PD modeling of $\beta$-lactam antibiotics: In vitro or in vivo models?
}

\author{
Bibiana Verlindo de Araujo ${ }^{1}$, Andrea Diniz ${ }^{2}$, Eduardo Célia Palma ${ }^{1}$, Cândida Buffé ${ }^{1}$ and Teresa Dalla Costa ${ }^{1}$ \\ A modified $E_{\text {max }}$-pharmacokinetic-pharmacodynamic (PK-PD) model was previously proposed in literature for describing \\ the antimicrobial activity of $\beta$-lactam antibiotics based on in vitro experiments. However, bacteria behave differently in vitro \\ and in vivo. Thus, the aims of this study were to model the killing effect of piperacillin (PIP) against Escherichia coli on \\ immunocompromised infected rats using this model and to compare the parameters obtained in vitro and in vivo for the same \\ bacteria/drug combination. The PK-PD parameters determined in vitro and in vivo were as follows: generation rate constant of \\ $1.30 \pm 0.10$ and $0.76 \pm 0.20 \mathrm{~h}^{-1}$, maximum killing effect of $3.11 \pm 0.27$ and $1.38 \pm 0.20 \mathrm{~h}^{-1}$ and concentration to produce \\ $50 \%$ of the maximum effect of $5.44 \pm 0.03$ and $1.31 \pm 0.27 \mu \mathrm{g} \mathrm{ml}^{-1}$, respectively. The comparison between the in vitro and \\ in vivo parameters was not straightforward and had to take into consideration the intrinsic differences of the models involved. \\ So far, the main application of the PK-PD model evaluated is for the comparison of different antimicrobial agent's potency \\ and efficacy, under equivalent conditions.
}

The Journal of Antibiotics (2011) 64, 439-446; doi:10.1038/ja.2011.29; published online 20 April 2011

Keywords: Escherichia coli; immunocompromised infected rats; in vitro model of infection; piperacillin; PK-PD modeling

\section{INTRODUCTION}

The cure of an infection is dependent on factors related to the invasive microorganism such as drug susceptibility, the host physiological and immunologycal conditions and the pharmacokinetic (PK) and pharmacodynamic (PD) characteristics of the antimicrobial agent used. An important step in addressing this issue is the combination of PK parameters of the antibiotic with its PDs properties against bacteria in a Pharmacokinetic-pharmacodynamic (PK-PD) model. PK-PD modeling links dose/concentration relationship (PK) and concentration/ effect relationship (PD), thereby facilitating the description and prediction of the time course of drug effects resulting from a certain dosing regimen. ${ }^{1,2}$

For the PK part of the model, the knowledge of the free interstitial levels of anti-infective agents at the biophase has drawn the attention of researchers, as the free concentrations at the site of infection are responsible for the bacterial killing and the outcome of anti-infective therapy. ${ }^{3}$ The feasibility of the prediction of free interstitial levels, determined by microdialysis, based on plasma PK parameters, has been demonstrated in literature for some $\beta$-lactam antibiotics such as piperacillin alone ${ }^{4}$ or in combination with tazobactam, ${ }^{5}$ ceftriaxone, ${ }^{6}$ cefaclor $^{7}$ and amoxicillin ${ }^{8}$ using healthy animals. However, some studies have demonstrated that infection changes the physiological characteristics of the infected tissue due to the inflammatory process developed by host aiming to eliminate the invasive organism, as observed in soft tissue infections, septic shock, pneumonia or vascular alterations associated to diabetes. ${ }^{9-12}$ In this context, it is not always possible to predict the antimicrobial-free fraction at the site of infection, based on the microdialysis data obtained in healthy tissue or unbound plasma levels.

The application of PK-PD modeling was successfully described in literature by Nolting et al. ${ }^{13}$ for the $\beta$-lactam antibiotic piperacillin (PIP) using a modified $\mathrm{E}_{\max }-$ model. This model proved to be useful to describe the association of piperacillin and tazobactam, a $\beta$-lactam inhibitor. ${ }^{14}$ The development of the model was conceptualized simulating the free concentration profiles of the antimicrobial agent expected at the infection site in humans against bacteria, using an in vitro model of infection, as described in majority of studies where antimicrobial PD is evaluated in PK-PD investigation. It has been shown, however, that bacteria have different growth behavior in vitro and in vivo, ${ }^{15,16}$ this event being specially associated to the medium conditions and the source of substrates. Besides, in the in vitro model of infection, the bacteria is in suspension, consequently more exposed to the antibiotic than in vivo, where they can adhere to cells and fibers present in the matrix making the access of the drug more difficult. ${ }^{16,17}$

In this context, to further explore the applicability of the PK-PD model developed, it is important to challenge the model's ability to describe antimicrobial effect over time in a more realistic scenario, using an experimental infection in vivo. Furthermore, the comparison between the parameters generated using an in vitro and an in vivo infection could be used to evaluate the ability of the in vitro

\footnotetext{
${ }^{1}$ Programa de Pós-Graduação em Ciências Farmacêuticas, Universidade Federal do Rio Grande do Sul, Porto Alegre-RS, Brasil and ${ }^{2}$ Faculdade de Farmácia, Universidade Estadual de Maringá, Maringá-PR, Brasil

Correspondence: Dr BV de Araujo, Universidade Federal do Rio Grande do Sul, Programa de Pós-Graduação em Ciências Farmacêuticas, Faculdade de Farmácia, Avenida Ipiranga, 2752-Bairro Santana, Porto Alegre RS CEP 90.610-000, Brasil.

E-mail: bibiana.araujo@.ufrgs.br

Received 19 November 2010; revised 4 February 2011; accepted 5 February 2011; published online 20 April 2011
} 
experiments to forecast the infection's outcome in vivo using the same drug/bacteria combination. Therefore, the aims of this study were to model the killing effect of piperacillin against Escherichia coli in immunocompromised infected rats using the same modified $\mathrm{E}_{\mathrm{max}^{-}}$ model described previously, ${ }^{13}$ and to compare the PK-PD parameters obtained in vivo with those determined by simulating in vitro against E.coli the free tissue levels of piperacillin expected at the infection site in humans, based on the assumption that the correlation between free skeletal muscle and total plasma concentrations established in healthy rodents ${ }^{4}$ would hold true in humans. For this study, besides the in vivo PD evaluation, the PK data used to carry out the PK-PD modeling was obtained by microdialysis at the infection site of immunocompromised E. coli-infected rats.

\section{MATERIALS AND METHODS}

\section{Animals, drugs and solvents}

All animal experiments described below were approved by the UFRGS Ethical in Research Committee (Protocol \#01-349).

Piperacillin was purchased from Sigma (St Louis, MO, USA). Analytical grade potassium phosphate monobasic and potassium phosphate dibasic were from Merck (Darmstadt, Germany) and HPLC grade acetonitrile was from Omnisolv (Gibbstown, NJ, USA). HPLC water from Millipore's Milli-Q System (Billerica, MA, USA) was used throughout the analysis.

\section{PIP quantification in plasma and microdialysate}

HPLC method has been adapted from literature ${ }^{5}$ for the determination of PIP in rat plasma and microdialysate samples using RP-C18 column (Waters Spherisorb ODS column (Milford, MA, USA) $-15 \mathrm{~cm} \times 4.6 \mathrm{~mm}$ I.D., $5 \mu \mathrm{m}$ particle size). The mobile phase $(0.1 \mathrm{M}$ phosphate buffer: acetonitrile, $80: 20$, v/v, $\mathrm{pH} 7.4)$ was pumped at a flow rate of $1.5 \mathrm{ml} \mathrm{min}^{-1}$ and the drug was monitored at $220 \mathrm{~nm}$.

Calibration curves in plasma were prepared in the range of $10-500 \mu \mathrm{g} \mathrm{ml}^{-1}$ by spiking rat plasma with PIP. For drug determination in rat plasma, $200 \mu \mathrm{l}$ samples were precipitated by the same volume of ice-cold acetonitrile. Subsequently, the mixture was centrifuged at $10621 \mathrm{~g}$ (Centrifuge Eppendorf 5417R, rotor $\mathrm{f}-45-3011)$ for $15 \mathrm{~min}$ at $21^{\circ} \mathrm{C}$. The supernatant $(200 \mu \mathrm{l})$ was used for injection into the chromatographic system. Tissue samples obtained by microdialysis $(20 \mu \mathrm{l})$ were injected directly without any sample processing. Calibration curves in Ringer solution in the range of $0.5-200 \mu \mathrm{g} \mathrm{ml}^{-1}$ were used to quantify the drug in the microdialysis samples. The method was validated according to FDA guidelines. ${ }^{18}$

\section{Experimental infection}

The infection model adapted for this study was previously described for mice. ${ }^{19}$ Neutropenia was induced in male pathogen-free Wistar rats (280-350 g) using cyclophosphamide: $150 \mathrm{mg} \mathrm{kg}^{-1}$ ip 5 days and $100 \mathrm{mg} \mathrm{kg}^{-1}$ ip 1 day before the experiment. The immunodepression achieved with cyclophosphamide treatment was evaluated by the total count of leukocytes conducted using the Shilling-Tourgau method in treated and control animals that received saline in a similar dosing regimen ( $n=3 /$ group). On the day of the experiment, the left tibial cranial muscle of the animal was inoculated with $0.1 \mathrm{ml}$ of a freshly prepared suspension containing $10^{6} \mathrm{CFU}$ per $\mathrm{ml}$ of Escherichia coli ATCC 25922. The inoculum was prepared from selected colonies incubated overnight on blood-agar plates.

\section{Pharmacokinetics experiments}

The neutropenic and infected animals were divided in three groups: $60 \mathrm{mg} \mathrm{kg}^{-1}$ (G1), $120 \mathrm{mg} \mathrm{kg}^{-1}$ (G2) and $240 \mathrm{mg} \mathrm{kg}^{-1}$ (G3), which received PIP after $2 \mathrm{~h}$ of inoculation ( $n=5 /$ group). The rats were anesthetized with urethane $\left(1.25 \mathrm{~g} \mathrm{~kg}^{-1}\right.$ ip) and the carotid artery was used for blood collection via an indwelling catheter. In the same experiment, the microdialysis probe was inserted in the animals' infected thigh muscle $1 \mathrm{~h}$ after inoculation. The microdialysis probe was perfused with Ringer's solution at a flow rate of $1.5 \mu \mathrm{min}^{-1}$ and it was allowed to equilibrate inside the muscle for $1 \mathrm{~h}$ before determination of relative recovery in vivo by retrodialysis. The relative recovery was determined at the infection site for all three groups, previously to the PK experiment, using a PIP solution of $1 \mu \mathrm{g} \mathrm{ml}^{-1}$ in Ringer at a flow rate of $1.5 \mu \mathrm{min}^{-1}$. Three $20 \mathrm{~min}$ samples were collected to determine the recovery. The perfusion solution was switched to plain Ringer and the probes were flushed for $1 \mathrm{~h}$ before animals drug dosing. PIP in saline was injected iv bolus into the femoral vein $(0.5 \mathrm{ml}$ per $100 \mathrm{~g})$ in order to reach 60,120 and $240 \mathrm{mg} \mathrm{kg}^{-1}$ doses. Microdialysate samples were collected over $20 \mathrm{~min}$ intervals and blood samples $(500 \mu \mathrm{l})$ were collected immediately before dosing and at 5 , $10,15,30,45,60,90$ and $120 \mathrm{~min}$ after drug administration. The animals remained anesthetized for the entire duration of the experiment.

PIP protein binding was determined by microdialysis in rat plasma samples obtained after i.v. administration of 60,120 and $240 \mathrm{mg} \mathrm{kg}^{-1}$ ( $n=3 /$ group) to immunocompromised animals. Blood samples were collected at 5, 10 and $15 \mathrm{~min}$ after dosing, and plasma was separated by centrifugation. A volume of $400 \mu \mathrm{l}$ of each plasma sample was placed in Eppendorf tubes and the microdialysis probes flushed with Ringer solution $1.5 \mu \mathrm{min}^{-1}$ were inserted into the system kept at $37^{\circ} \mathrm{C}$. After equilibration of the probes into the media, three samples were collected in $20 \mathrm{~min}$ intervals. The microdialysate and the plasma samples were analyzed by HPLC and the free levels of PIP in each sample were determined by the ratio between the microdialysate and total plasma concentration.

Total plasma compartmental analysis was performed using the computer program Scientist v. 2 (MicroMath, St Louis, MO, USA). The relationship between total plasma levels and free tissue levels was evaluated performing a simultaneous fitting of total plasma concentration to equation (1), two compartment model, and free tissue concentrations to equation (2): ${ }^{5}$

$$
C_{\text {plasma, total }}=\mathrm{a} e^{-\alpha t}+\mathrm{b} e^{-\beta t}
$$

$$
C_{\text {tissue, free }}=\frac{f_{\mathrm{u}} f(\beta \mathrm{a}+\alpha \mathrm{b})}{(\alpha-\beta)}\left(e^{-\beta t}-e^{-\alpha t}\right)
$$

where $C_{\text {plasma,total }}$ is the total plasma concentration and $C_{\text {tissue, free }}$ is the free muscle concentration at time $t$, respectively; $\alpha$ and $\beta$ are the hybrid constants for the distribution and elimination phase, respectively, being $\alpha$ higher than $\beta$; $\mathrm{a}$ and $\mathrm{b}$ as the corresponding zero-time intercepts; and $f_{\mathrm{u}}$ is the free fraction of piperacillin in plasma and ' $f$ ' is a proportionality factor used to allow the simultaneous fitting of both data sets. A similar weighting factor was used for all the data points. The compartmental PK parameters were determined using classical equations. ${ }^{20}$

Microdialysis probes in vitro relative recoveries were determined by retrodialysis using PIP $1 \mu \mathrm{g} \mathrm{m}^{-1}$ in Ringer at a flow rate of $1.5 \mu \mathrm{min}^{-1}$ as previously described. ${ }^{4}$

\section{Pharmacodynamics experiments}

In vitro model. The model used in this work was the same described by Nolting et al., ${ }^{13}$ but the concentration time profile simulated in vitro was established in order to be equivalent to the free tissue concentrations expected in immunocompromised and infected rats after iv administration of a $120 \mathrm{mg} \mathrm{kg}^{-1}$ dose. To predict this profile, rats PK parameters obtained from this study were used as follows: maximum drug concentration in serum $\left(C_{\max }\right)$ of $80 \mu \mathrm{g} \mathrm{ml}^{-1}$, half-life $\left(t_{1 / 2}\right)$ of $0.5 \mathrm{~h}$ and elimination rate constant $\left(k_{e l}\right)$ of $1.38 \mathrm{~h}^{-1}$. The free peak concentration was calcd assuming a protein binding of $47 \%$.

In vivo model. In a previous pilot study, the treatment of infected animals with PIP $60 \mathrm{mg} \mathrm{kg}^{-1}$ was not effective, probably because the drug's short halflife in rats $(0.5 \mathrm{~h})$ associated with the time-dependent antimicrobial effect of PIP. On the basis of these results, only the higher doses were tested in the PD experiments.

The animals were divided in six groups, which received one of the following treatments: PIP 120 or $240 \mathrm{mg} \mathrm{kg}^{-1}$ in three different dose regimens q8h, q6h or $\mathrm{q} 4 \mathrm{~h}$ for $24 \mathrm{~h}$. The control group was immunocompromised and infected in the same manner, but was not treated with the drug.

On the day of the experiment, after $3 \mathrm{~h}$ of bacteria inoculation, the first dose of piperacillin was administered in the penile vein and the subsequent doses 
were administered in the same manner following the respective dosing regimen. At pre-determined time points, specific for each dosing interval ( $\mathrm{q} 4 \mathrm{~h}$ at $0,2,4$, $6,8,10,12,14,16,18,20,22$ and $24 \mathrm{~h}$; q6h at $0,3,6,9,12,15,18,21$ and $24 \mathrm{~h}$; $\mathrm{q} 8 \mathrm{~h}$ at $0,4,8,12,16,20$ and $24 \mathrm{~h}$ ), the animals were euthanized by cervical dislocation. The animals of the control group were killed at $0,3,6,9$ and $24 \mathrm{~h}$ after inoculation. The tibial cranial muscles were surgically removed and homogenized with the aid of $10 \mathrm{ml}$ of sterile saline $(0.9 \% \mathrm{NaCl})$ with a tissue homogenizer. Viable counts were determined on sheep blood agar (triptic soy agar and sheep blood $10 \%$ ) by plating duplicate $100 \mu \mathrm{l}$ samples of serially 10 -fold dilutions of the homogenate. The number of CFU per $\mathrm{ml}\left(\mathrm{CFU} \mathrm{ml}^{-1}\right)$ was determined after $24 \mathrm{~h}$ of incubation at $37^{\circ} \mathrm{C}$.

\section{PK-PD modeling}

A modified $\mathrm{E}_{\max }$-model, previously described, was used to model the bacterial killing effect of piperacillin in vitro and in vivo against E. coli ATCC 25922: ${ }^{13}$

$$
\frac{\mathrm{d} N}{\mathrm{~d} t}=\left(k-\frac{k_{\max } C_{\mathrm{t}}}{\mathrm{EC}_{50}+C_{\mathrm{t}}}\right) N
$$

where $\mathrm{dN} / \mathrm{d} t$ is the change in number of bacteria as a function of time (PD effect); $k\left(\mathrm{~h}^{-1}\right)$ is the bacteria generation rate constant in the absence of any drug (data from the control group); $k_{\max }\left(\mathrm{h}^{-1}\right)$ is the maximum killing effect; $C_{\mathrm{t}}\left(\mu \mathrm{g} \mathrm{ml}^{-1}\right)$ is the free concentration of piperacillin at the infection site, determined by microdialysis; and $\mathrm{EC}_{50}\left(\mu \mathrm{g} \mathrm{ml}^{-1}\right)$ is PIP concentration required to produce $50 \%$ of the maximum killing effect. In this equation, the drug effect is measured by the inhibition of growth or killing (reduction of number of bacteria). In the absence of drug, bacteria growth rate $(k)$ determines the increasing number of bacteria as a function of time. When enough free drug is present in the tissue, actual killing of bacteria is induced and the resultant killing rate constant is $k-k_{\max }$. For the fitting, the values of $k$ in vivo were fixed as the average value determined after a first fitting of the experimental data.

To model the drug-killing effect after the different dosing regimens investigated, the term related to concentration on equation $(2)\left(C_{\mathrm{t}}\right)$ was replaced by equation (3). The parameters used for equation (2) were determined for piperacillin 60,120 and $240 \mathrm{mg} \mathrm{kg}^{-1}$ at the same experimental conditions and are shown in Table 1.

\section{Statistical analysis}

The goodness of the curve fit was evaluated by the model selection criteria (MSC), a modified Akaike function, as well as the correlation coefficient $(r)$ given by the computer program SCIENTIST v.2. (MicroMath). The MSC value is the information content of the fit of the model, and the higher the value, the better is the fit. The PK parameters determined for the three PIP doses were compared by analysis of variance $(\alpha=0.05)$.

Table 1 Piperacillin compartmental pharmacokinetic parameters determined after simultaneous fitting of plasma and tissue concentration profiles after 60,120 and $240 \mathrm{mg} \mathrm{kg}^{-1}$ iv bolus administration to immunocompromised, and $3 \mathrm{~h} \mathrm{E}$. coli-infected rats $(n=5 / \text { group })^{\mathrm{a}}$

\begin{tabular}{lccc}
\hline PK Parameters & $60 \mathrm{mg} \mathrm{kg}^{-1}$ & $120 \mathrm{mg} \mathrm{kg}^{-1}$ & $240 \mathrm{mg} \mathrm{kg}^{-1}$ \\
\hline Half-life (min) & $27 \pm 17$ & $26 \pm 13$ & $33 \pm 5$ \\
$\mathrm{Vc}\left(\mathrm{kg}^{-1}\right)$ & $0.09 \pm 0.03$ & $0.09 \pm 0.02$ & $0.15 \pm 0.01^{\mathrm{b}}$ \\
$\mathrm{Vdss}\left(\mathrm{kg}^{-1}\right)$ & $0.17 \pm 0.09$ & $0.19 \pm 0.08$ & $0.28 \pm 0.03^{\mathrm{b}}$ \\
$\mathrm{CL}\left(\mathrm{I} \mathrm{h}^{-1} \mathrm{~kg}^{-1}\right)$ & $0.29 \pm 0.05$ & $0.34 \pm 0.10$ & $0.43 \pm 0.07$ \\
$\mathrm{AUC} \mathrm{O}_{\infty} / \mathrm{D}\left(\mu \mathrm{g} \mathrm{min} \mathrm{ml} \mathrm{m}^{-1}\right)$ & $214 \pm 37$ & $179.6 \pm 50.2$ & $141.5 \pm 20.1$ \\
$\alpha\left(\mathrm{min}^{-1}\right)$ & $0.175 \pm 0.027$ & $0.190 \pm 0.040$ & $0.195 \pm 0.050$ \\
$\beta\left(\mathrm{min}^{-1}\right)$ & $0.028 \pm 0.014$ & $0.030 \pm 0.010$ & $0.022 \pm 0.003$ \\
$\mathrm{~F}$ & $0.35 \pm 0.15$ & $0.34 \pm 0.09$ & $0.34 \pm 0.12$ \\
$\mathrm{MSC}$ & $0.4-3.6$ & $0.9-2.1$ & $1.5-3.2$
\end{tabular}

Abbreviations: AUC, area under the curve; $\mathrm{CL}$, clearance; MSC, model selection criteria; PK, pharmacokinetic. $V_{C}$, volume of central compartiment. Vdss, volume of distribution at steady sate.

Data are expressed as mean $\pm \mathrm{s}$.

$P<0.05$, compared with the values at 60 and $120 \mathrm{mg} \mathrm{kg}^{-1}$.

\section{RESULTS}

\section{HPLC method validation}

The HPLC method was validated according to FDA guidance. ${ }^{18}$ Linear calibration curves could be obtained in investigated ranges with coefficients of correlation of more than 0.993 for plasma and microdialysate. The limits of quantification were $10 \mu \mathrm{g} \mathrm{ml}^{-1}$ in plasma and $0.5 \mu \mathrm{g} \mathrm{ml}^{-1}$ in microdialysate. Inter- and intraday variability were determined for different quality control concentrations in plasma (10, 150 and $400 \mu \mathrm{g} \mathrm{ml}^{-1}$ ) and microdialysate samples (0.8, 50, $150 \mu \mathrm{g} \mathrm{ml}^{-1}$ ) were less than 14.1 and $13.2 \%$, respectively. The method showed an accuracy within 15\% for plasma and microdialysate samples (95.4 and 107.4\%).

\section{Experimental infection}

The neutropenia induced in the animals using cyclophosphamide was confirmed by counting the total plasma leukocytes in the treated and control groups. The average total count for the treated group was $240 \pm 40$ cells per $\mathrm{ml}$ and for the control group was $11400 \pm 1200$ cells per ml.

The bacteria generation rate constant was determined in the logphase of the in vitro and in vivo curves (Figure 1). The average generation rate constant in vivo was $0.76 \pm 0.20 \mathrm{~h}^{-1}$, and was determined from the data of control group of each experiment. For the modeling, $\mathrm{k}$ values were fixed as $0.76 \mathrm{~h}^{-1}$ for the in vivo fitting. The generation rate constant in vitro was $1.30 \pm 0.02 \mathrm{~h}^{-1}$.

\section{Pharmacokinetics experiments}

The in vitro recovery was found to be $14.2 \pm 3.4 \%$ and the in vivo recovery determined in infected muscle was $13.5 \pm 3.7 \%$, statistically similar to the in vitro one $(\alpha=0.05)$, for all groups investigated. The in vivo recovery was in the same order of magnitude of the average recovery reported in literature for the same probe and drug determined in healthy rat skeletal muscle $(10.1 \pm 0.9 \%)$ (ref. 4$)$.

The free fractions of PIP determined by microdialysis in rat plasma were found to be $54 \pm 27,53 \pm 11$ and $69 \pm 18 \%$, for the 60,120 and $240 \mathrm{mg}$ per $\mathrm{kg}$ dose, respectively. Although these values did not differ significantly from each other $(P<0.05)$, the value at the highest dose was increased, compared with those at the lower dose. Therefore, each value was applied for the respective dose in the tissue penetration study.

The PK parameters derived from the compartmental analysis of PIP plasma profiles after administration of 60,120 and $240 \mathrm{mg}$ per $\mathrm{kg}$

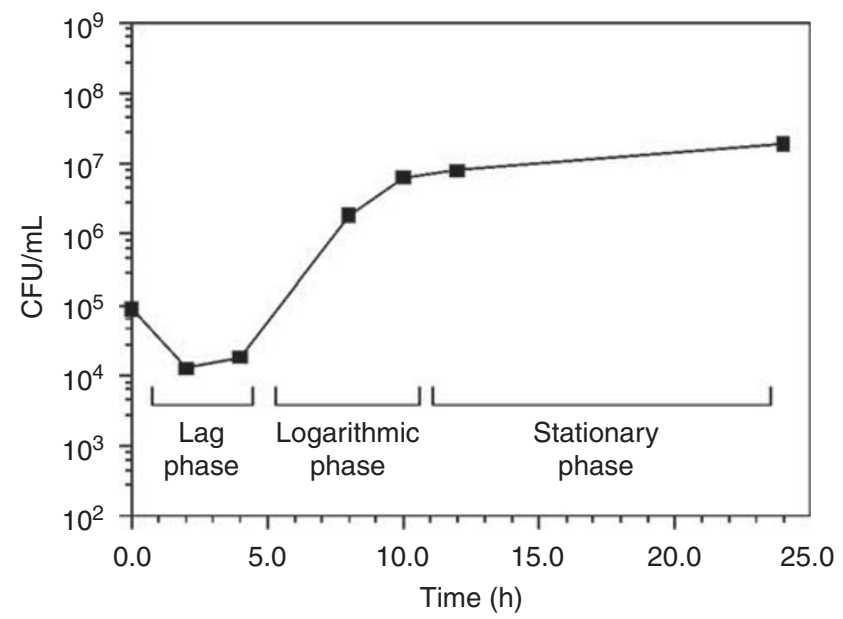

Figure 1 Escherichia coli ATCC 25922 growth curve in vivo. 
doses to immunocompromised and $3 \mathrm{~h} \mathrm{E}$. coli infected animals are shown in Table 1. Statistical analysis showed differences among the parameters volume of central compartiment $(\mathrm{Vc})$ and apparent volume of distribution at steady sate $\left(\mathrm{Vd}_{\mathrm{ss}}\right)$ for the higher dose $\left(240 \mathrm{mg} \mathrm{kg}^{-1}\right)$ in comparison with the lower doses (120 and $\left.60 \mathrm{mg} \mathrm{kg}^{-1}\right)$. No statistical differences were observed among the other PK parameters for the three doses evaluated $(\alpha=0.05)$.

Figure 2 shows the average total plasma levels of the drug after the investigated doses. A two-compartment model adequately described the data in all cases. The free interstitial PIP levels determined by microdialysis, as well as the predicted profiles based on plasma data are also shown. As it can be seen, free tissue levels were predicted for all groups of animals using the proportionality factor and the PK parameters derived from fitting the plasma data to a two-compartment model equation. The proportionality factor was determined to be $0.35 \pm 0.15,0.34 \pm 0.09$ and $0.34 \pm 0.12$ for 60,120 and $240 \mathrm{mg}$ per $\mathrm{kg}$ doses, respectively.

\section{Pharmacodynamics studies}

The curve fittings obtained for PIP $120 \mathrm{mg} \mathrm{kg}^{-1}$ in vitro model are shown in Figure 3 and the PK-PD parameters of these curve fittings are shown in Table 2. The results of in vivo studies for 120 and $240 \mathrm{mg} \mathrm{kg}^{-1}$ administered $\mathrm{q} 4 \mathrm{~h}, \mathrm{q} 6 \mathrm{~h}$ and $\mathrm{q} 8 \mathrm{~h}$ are shown in Figure 4. The values obtained for the PK-PD parameters of these curve fittings are shown in Table 3 and have not shown statistical difference for the different dosing regimens tested $(\alpha=0.05)$.

\section{DISCUSSION}

The adequate selection of the animal model to study antimicrobial PK-PD correlation is of fundamental importance for the usefulness of the outcome. The most commonly used animal infection model to investigate PK-PD correlation is the neutropenic mouse thigh model. Some advantages of this model for PK-PD investigations are: ${ }^{19}$ the granulocitopenia can be induced in the animals eliminating the influence of neutrophyls and other polymorphonuclears on the infection, allowing the determination of the antimicrobial effect; the bacteria counting at the infection site can be easily processed (PD) and the plasma levels of the drug are easily accessed (PK). Finally, because of the fast antimicrobial elimination, the model allows the investigation of several dosing regimens leading to the establishment of $\mathrm{PK}$ and PD correlation. Although mice are traditionally used for the thigh infection model, rats present some advantages for PK studies: blood samples can be drawn for longer periods of time, the animal can be kept anesthetized and microdialysis can be carried out concomitantly with blood sampling. Assuming that PKs and PDs should be investigated in the same animal under the same experimental conditions, the mouse thigh infection model was adapted to rats in this work.

To assure that the infection model was adapted to rats, the total leukocytes count was conducted after the administration of cyclophosphamide. The results showed that the treated animals presented total count lower than 300 leukocytes per $\mathrm{ml}$ indicating severe neutropenia. ${ }^{19}$ Another experiment conducted to assure that the infection model had been successfully adapted to rats was the determination of the bacterial growth curve (Figure 1). The result showed that it was possible to visualize all the characteristic phases of the bacteria growth: ${ }^{21}$ the lag-phase, showing that it took $3 \mathrm{~h}$ for the bacteria to adapt to the muscle conditions, the logarithmic-phase, necessary to obtain the effect of $\beta$-lactam antibiotics such as PIP, and the achievement of a plateau (stationary phase). These results showed that the adaptation of the infection was successful and that the contribution of
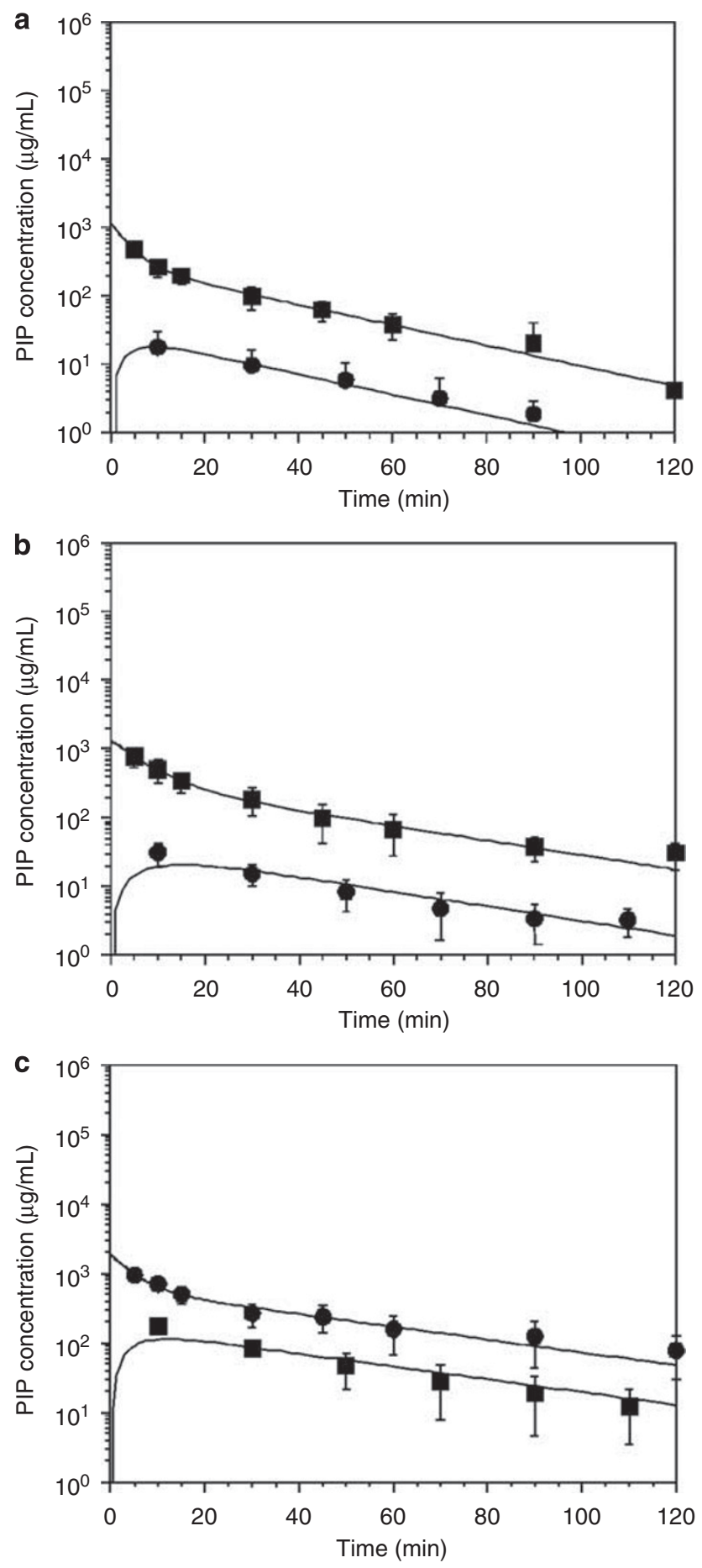

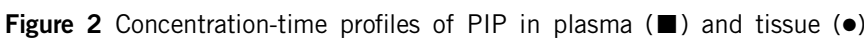
after iv bolus dosing of $60 \mathrm{mg} \mathrm{kg}^{-1}$ (a), $120 \mathrm{mg} \mathrm{kg}^{-1}$ (b) and $240 \mathrm{mg} \mathrm{kg}^{-1}$ (c) to immunocompromised infected rats ( $n=5$ /group). The plasma data were fitted to a two-compartment model (equation (1)). The line for tissue levels is not fitted to the measured microdialysis data, but is predicted based on the plasma data using equation (2) (average \pm s.d.).

the immune system for the bacteria killing at the infection site was significantly reduced.

Considering the tissue penetration, is known that only the free levels at the biophase are responsible for the pharmacological activity of drugs in general. Although plasma levels have been used to correlate 

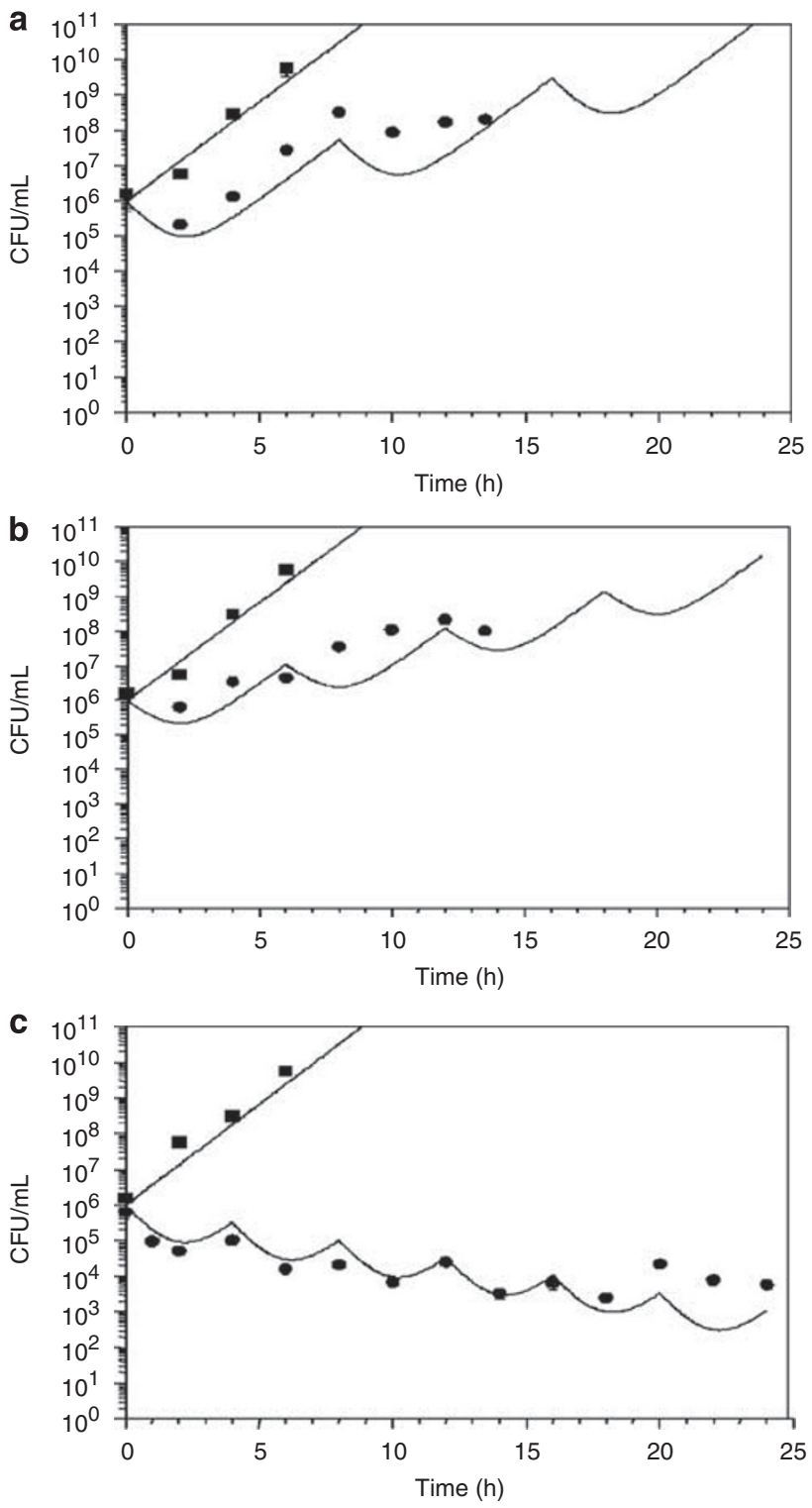

Figure 3 Curve fitting of PIP antimicrobial effect in vitro against $E$. coli: (ם) control group, (•) treated group with PIP $120 \mathrm{mg} \mathrm{kg}^{-1}$ (a) q4h, (b) q6h and (c) q8h (average \pm s.d.).

with PD bacterial killing effect, ${ }^{22}$ the free tissue levels of the drug at the infection site are more relevant for the bacterial-killing effect. Nowadays, free interstitial levels of different tissues can be determined using microdialysis. $^{23}$

Piperacillin therapeutic doses for the treatment of human infections are 60 and $120 \mathrm{mg} \mathrm{kg}^{-1}$ given four times a day. ${ }^{24}$ The use of these two doses was initially intended in this work in order to treat the experimental $E$. coli infection produced in the immunocompromised rats. The $60 \mathrm{mg}$ per $\mathrm{kg}$ dose, however, presented an insignificant killing effect for the six times a day regimen, resulting in a curve similar to the non-treated control group (data not shown). This result can be attributed to the half-life of piperacillin in rats, which was shown to be around $30 \mathrm{~min}$, whereas in humans it is twice this value. $\beta$-lactam antibiotics are classified as time-dependent bacterial-killing drugs meaning that the extent of the microbial killing is primarily dependent on the duration of the exposure to concentrations equivalent to low
Table 2 Pharmacokinetic-pharmacodynamic parameters of the in vitro curve fitting of piperacillin using bacteria rate constant of $1.30 \mathrm{~h}^{-1}$

\begin{tabular}{lcccc}
\hline & \multicolumn{3}{c}{$120 \mathrm{mgkg}^{-1}$} \\
\cline { 2 - 4 } Parameter & $q 4 h$ & $q 6 h$ & $q 8 h$ & Average \pm s.d. \\
\cline { 2 - 4 } $\mathrm{EC}_{50}\left(\mu \mathrm{g} \mathrm{ml}^{-1}\right)$ & $5.41 \pm 0.02$ & $5.46 \pm 0.03$ & $5.47 \pm 0.03$ & $5.4 \pm 0.03$ \\
$\mathrm{k}_{\max }\left(\mathrm{h}^{-1}\right)$ & $3.3 \pm 0.30$ & $2.8 \pm 0.25$ & $3.2 \pm 0.29$ & $3.1 \pm 0.27$ \\
MSC & -1.88 & 0.62 & 0.60 & \\
$r^{2}$ & $0.83 \pm 0.09$ & $0.99 \pm 0.05$ & $0.99 \pm 0.07$ & $0.94 \pm 0.05$ \\
\hline
\end{tabular}

Abbreviation: MSC, model selection criteria

multiples of the MIC. ${ }^{13}$ Consequently, the shorter half-life in rats will lead to PIP concentrations below MIC faster than in humans, resulting in lack of bactericidal effect for the smaller dose. Piperacillin MIC for E. coli ATCC 25922 used in this work was determined to be $2-4 \mu \mathrm{g} \mathrm{ml}^{-1}$, consistent with literature. To overcome the low concentrations problem, PIP doses investigated in infected animals were 120 and $240 \mathrm{mg} \mathrm{kg}^{-1}$. The higher PIP dose, however, led to an increased free fraction in plasma, which was not observed for the 60 and $120 \mathrm{mg}$ per $\mathrm{kg}$ doses. This result could be explained by saturation of plasma proteins. To overcome this issue, the free plasma fraction determined for each dose was used for the predictions of piperacillin interstitial unbound levels for the corresponding dose using equation (2).

The tissue penetration study revealed that infection changed the relationship between total plasma and free tissue concentration of PIP. Nolting et al. ${ }^{4}$ studied this relationship for the same bacteria and drug in healthy Wistar rats and were able to predict the free tissue levels based on total plasma concentration without the need of a proportionality factor, indicating that this drug distribution is governed by passive diffusion process. In this study, however, the proportionality factor was necessary to allow the prediction of free tissue concentrations based on plasma PK parameters, indicating that infection caused physiological changes in muscle such as increase in vascular permeability leading to increase in protein concentration at the infection site, increase in tissue temperature and $\mathrm{pH}$ alterations that would ultimately lead to an around 30\% decrease in free interstitial levels of PIP. Joukhadar et al. ${ }^{10}$ studied the tissue penetration of piperacillin in skeletal muscle and s.c. adipose tissue in patients with septic shock, using microdialysis, and observed that the free levels of piperacillin in these situations were 5-10 times lower than the corresponding free plasma concentrations, indicating the infectious process changed the penetration of this antimicrobial, reducing its clinical effectiveness. The difference between this study and that reported by Joukhadar et al. is that in the present one the animals had a localized infection instead of a septic shock that definitively alters body homeostasis. A potential explanation for plasma to tissue gradient observed for PIP in infected tissues is that the drug is a zwitterions, and as such, differences in $\mathrm{pH}$ between plasma water and interstitial fluid may cause it to be ionized and hinder its diffusion across membranes. Other possible explanations include the presence of peripheral chemical degradation that may occur because of PIP instability in acid $\mathrm{pH}$.

The PD experiments, showed that the in vivo bacterial-killing effect of piperacillin obtained for the 120 and $240 \mathrm{mg}$ per $\mathrm{kg}$ doses were dependent on the dosing interval investigated: $\mathrm{q} 4 \mathrm{~h}, \mathrm{q} 6 \mathrm{~h}$ and $\mathrm{q} 8 \mathrm{~h}$ (Figure 4). It can also be depicted from this figure that, for all the situations investigated in vivo, the PK-PD model used adequately described the experimental data. The goodness of curve fit can be 

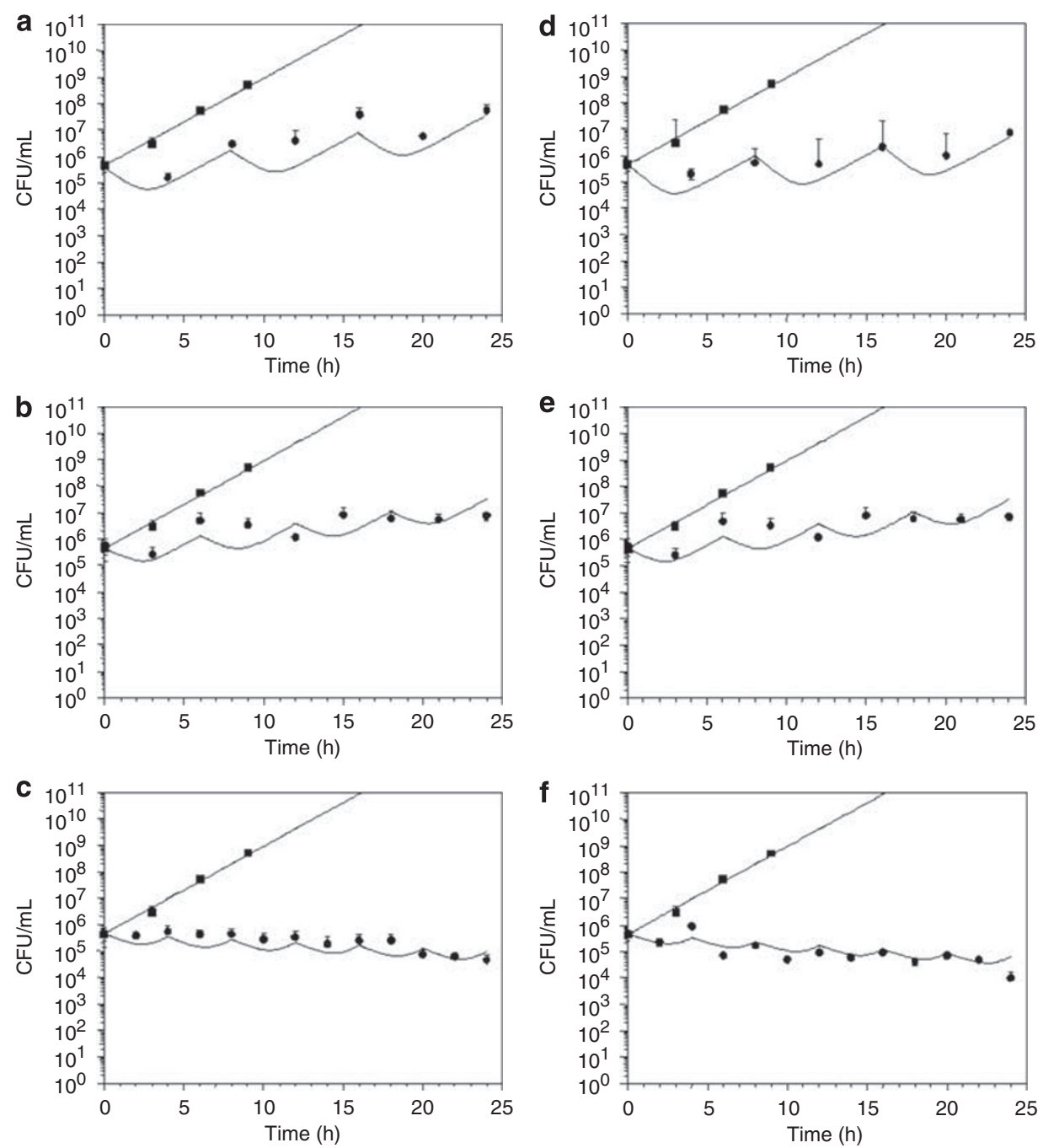

Figure 4 Curve fitting of PIP antimicrobial effect in vivo against E. coli infection in immunocompromised rats. Left panel: ( $\mathbf{\square})$ control group, $(\bullet)$ treated group with PIP $120 \mathrm{mg} \mathrm{kg}^{-1}$ (a) q8h, (b) q6h and (c) q4h. Right panel: (ש) control group, (•) treated group with PIP $240 \mathrm{mg} \mathrm{kg}^{-1}$ (d) q8h, (e) q6h and (f) q4h (average \pm s.d.).

Table 3 Pharmacokinetic-pharmacodynamic parameters of the in vivo curve fitting of piperacillin using bacteria generation rate constant of $0.76 \mathrm{~h}^{-1}$

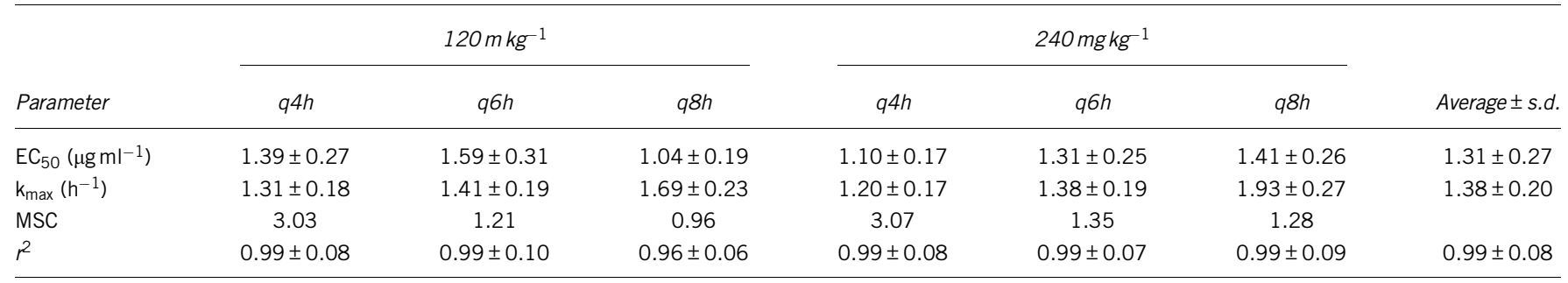

Abbreviation: MSC, model selection criteria

confirmed by the values of MSC and correlation coefficient obtained (Table 3).

The comparison of the different dosing intervals for the same total daily dose (Figures $4 \mathrm{c}$ and $\mathrm{d}$ ) showed an increasing magnitude of killing effect for the shorter dosing intervals. As mentioned before, this is consistent with the classification of $\beta$-lactam antibiotics as time-dependent killing antimicrobials. ${ }^{25}$
The time dependency of PIP effect can also be observed when comparing the same dosing regimen for the 120 and $240 \mathrm{mg}$ per $\mathrm{kg}$ doses (Figures $4 \mathrm{a}$ and $\mathrm{d}$ for $\mathrm{q} 8 \mathrm{~h}, \mathrm{~b}$ and $\mathrm{e}$ for $\mathrm{q} 6 \mathrm{~h}$, and $\mathrm{c}$ and $\mathrm{f}$ for $\mathrm{q} 4 \mathrm{~h}$ ). The free interstitial peak concentration observed at the infection site and used to model the PK-PD data was around $40 \mu \mathrm{g} \mathrm{ml}^{-1}$ for $120 \mathrm{mg}$ per $\mathrm{kg}$ dose and $120 \mu \mathrm{g} \mathrm{ml}^{-1}$ for the $240 \mathrm{mg}$ per $\mathrm{kg}$ dose. Taking into consideration the MIC of PIP for the E. coli used in this study, it can 
be expected that the concentrations at the infection site are close to the MIC after 3-6 half-lives for both doses, resulting in bacterial re-growth at approximately the same time. These killing and re-growth profiles can be observed in Figure 4 for both doses.

It can be seen that the model adequately described the experimental data for all dosing regimens investigated. The $\mathrm{q} 6 \mathrm{~h}$ and $\mathrm{q} 8 \mathrm{~h}$ regimens were not effective, similar to the results obtained in vivo (Figures $4 \mathrm{a}$ and $\mathrm{d}$ ), and bacteria re-growth determined the end of the experiment after $12 \mathrm{~h}$. For q4h (Figure 4a), bacteria killing were observed without infection eradication up to $24 \mathrm{~h}$. The PK/PD parameters values obtained after the in vitro data fitting (Table 2) differed from those determined using in vivo data, although the PK profile simulated in vitro was the same observed in the animals.

The PD parameters obtained by the PK-PD modeling of PIP bacterial killing effect were the maximum killing effect $\left(k_{\max }\right)$ and the concentration to produce $50 \%$ of the maximum effect $\left(\mathrm{EC}_{50}\right)$ (Tables 2 and 3 ). The $\mathrm{EC}_{50}$ and $k_{\max }$ were similar for the different dosing regimens investigated in vivo as it was previously observed with the results from in vitro time-kill curves, ${ }^{13}$ indicating that they are characteristics of the bacteria/drug interaction and independent of the doses or dosing regimen investigated.

The comparison between the parameters determined for the same infection model in vitro and in vivo was one of the goals of this work. The value of the E. coli ATCC 25922 generation rate constant obtained in vitro was determined to be $1.30 \pm 0.02 \mathrm{~h}^{-1}$ higher than the value determined in vivo $\left(0.76 \pm 0.20 \mathrm{~h}^{-1}\right)$ considering the control experiments performed concomitantly to the treatments. These results show that the bacterial generation time in vitro (approx. $30 \mathrm{~min}$ ) was faster than in vivo (approx. $60 \mathrm{~min}$ ), which could be foreseen. According to literature, in in vitro environment bacteria differ from those cultivated in vivo in terms of amino acid composition, synthesis of toxic metabolites and metabolic rate. Although bacteria are in general more metabolically active in vivo than in vitro, it has been shown that the replication generally occurs faster in an in vitro environment. ${ }^{26}$

The maximum killing effect $\left(k_{\max }\right)$ obtained in vivo $(1.38 \pm$ $0.20 \mathrm{~h}^{-1}$ ) was two times smaller that the value obtained in the in vitro experimental infection $\left(3.11 \pm 0.27 \mathrm{~h}^{-1}\right)$ demonstrating that it took longer to eradicate the bacteria when the experimental infection took place in vivo. The PIP killing rate constant for the two situations can be determined by the difference between the generation rate constant and the maximum killing effect $\left(k-k_{\max }\right)$ (equation (3)). The killing rate constant in vitro $\left(1.8 \mathrm{~h}^{-1}\right)$ was almost three times bigger than the killing constant in vivo $\left(0.62 \mathrm{~h}^{-1}\right)$. One possible explanation for this phenomenon is the drug mechanism of action. $\beta$-lactam antibiotics bactericidal mechanism involves the inhibition of the cell-wall synthesis and the drug is active during the bacteria growth phase, which was shown to be faster in vitro, creating better conditions for PIP activity.

In the same manner, the concentration necessary to produce $50 \%$ of the maximum effect $\left(\mathrm{EC}_{50}\right)$ in vivo $\left(1.31 \pm 0.27 \mu \mathrm{g} \mathrm{ml}^{-1}\right)$ was almost four times smaller than the value obtained in vitro $\left(5.44 \pm 0.03 \mu \mathrm{g} \mathrm{ml}^{-1}\right)$. Because the bacteria is more available to antibiotic attack in vitro one could expect that the $\mathrm{EC}_{50}$ would be smaller at this situation, assuming the same maximum killing effect in vitro and in vivo. However, the maximum killing effect obtained for the two situations was not equivalent, thus the values of $\mathrm{EC}_{50}$ can not be compared. One factor that can not be forgotten is that the neutropenia observed confirms that the number of granulocytes was reduced in the immunocompromised animals but the other host defense factors are still present in the animal and could still contribute to the final killing effect in opposition to the in vitro situation where the drug is the only factor responsible for the bactericidal effect. This factor by itself can not account for the $\mathrm{EC}_{50}$ differences observed. The importance of the bacteria different generation rate constant in vitro and in vivo for the $\beta$-lactam antimicrobial killing effect was also pointed out by Bonapace et al. ${ }^{15}$ when studying ticarcillin against Pseudomonas sp.

Another comparison can be made between the in vitro parameters determined in this study and the ones previously reported by Nolting et al. ${ }^{13}$ In the in vitro experiment reported in that study, the bacteria was exposed to concentrations above the MIC for shorter periods of time because the immunocompromised rat half-life of $30 \mathrm{~min}$ was simulated, whereas piperacillin human half-life simulated in literature was $1 \mathrm{~h} .{ }^{13}$ The resulting values of $k_{\max }\left(3.11 \pm 0.02 \mathrm{~h}^{-1}\right.$ for rats and $3.19 \pm 1.39 \mathrm{~h}^{-1}$ for humans) and $\mathrm{EC}_{50}\left(5.44 \pm 0.03 \mu \mathrm{g} \mathrm{ml}^{-1}\right.$ for rats and $5.17 \pm 1.81 \mu \mathrm{g} \mathrm{ml}^{-1}$ for humans) reported were similar for both experiments. However, the killing curves were different: bacterial eradication was obtained when simulating the humans' free PIP profile expected in the infection site after distinct dosing regimens while only a reduction of the initial inoculum was obtained when the immunocompromised rats' free-tissue levels were simulated. Because the only difference between these two experiments was the drug halflife, one can conclude that, for a fixed bacteria generation rate constant, the drug PKs determines the infection outcome.

Putting together these two comparisons, in vitro vs in vivo (present study) and in vitro animals vs in vitro humans, ${ }^{13}$ it becomes clear that the generation rate constant affects the parameters of the $\mathrm{E}_{\max }$ PK-PD model to a higher extent than the half-life. The half-life parameter, however, is fundamental in defining the shape and outcome of the killing profiles for the same generation rate constant.

\section{CONCLUSIONS}

The results presented in this work showed that the modified $\mathrm{E}_{\max }{ }^{-}$ model used was adequate to fit the in vivo reduction of the number of bacteria at the infection site as a function of time. The comparison between the in vitro and in vivo PK-PD parameters is not straightforward and several factors related to the intrinsic differences between the experimental infection models involved have to be taken into consideration.

It would be premature, however, to suggest that such PD studies should henceforth be conducted by using only in vivo systems instead of in vitro infection models. The in vitro systems have successfully been used for a long time for comparing antimicrobials potency and for the understanding of the factors that may limit the efficacy of antimicrobials in vivo.

The results presented in this paper indicate that the antimicrobial activity evaluated in vitro should be followed by the evaluation of the drug in an in vivo infection model to ensure the consistency of the results obtained and to approach the results to the clinical outcomes expected. At this moment, the main application of the PK-PD models such as the one evaluated here is for the comparison of different antimicrobial agents' potency and efficacy under equivalent conditions.

1 Schmidt, S., Barbour, A., Sahre, M., Rand, K. H. \& Derendorf, H. PK/PD: new insights for antibacterial and antiviral applications. Curr. Opin. Pharmacol. 8, 549-556 (2008).

2 Derendorf, H. \& Meibohm, H. Modeling of pharmacokinetic/pharmacodynamic (PK/PD) relationships: concepts and perspectives. Pharm Res. 16, 176-185 (1999).

3 Mouton, J. W. et al. Tissue concentrations: do we ever learn? J. Antimicrob. Chemother. $61,235-237$ (2008) 
4 Nolting, A., Dalla Costa, T. \& Derendorf, H. Determination of Free Extracellular Concentration of Piperacillin by Microdialysis. J. Pharm. Sci. 85, 369-372 (1996).

5 Dalla Costa, T., Nolting, A., Kovar, A. \& Derendorf, H. Determination of Free Interstitial Concentrations of Piperacillin-Tazobactam Combinations by Microdialysis. J. Ant. Chemother. 42, 769-778 (1998).

6 Kovar, A., Costa, T. D. \& Derendorf, H. Comparison of plasma and free tissue levels of ceftriaxone in rats by microdialysis. J. Pharm. Sci. 86, 52-56 (1997).

7 De la Pena, A. et al. Penetration of Cefaclor Into the Interstitial Space Fluid of Skeletal Muscle and Lung Tissue in Rats. Pharm. Res 18, 1310-1314 (2001).

8 Marchand, S., Chenel, M., Lamarche, I. \& Couet, W. Pharmacokinetic Modeling of Free Amoxicillin Concentrations in Rat Muscle Extracellular Fluids Determined by Microdialysis. Antimicrob. Agents Chem. 49, 3702-3706 (2005).

9 Joukhadar, C. et al. Penetration of moxifloxacin into healthy and inflamed subcutaneous adipose tissue in humans. Antimicrob. Agents Chemother. 47, 3099-3103 (2003).

10 Joukhadar, C. et al. Impared target site penetration of beta-lactam may account for therapeutic failure in patients with septic shock. Crit. Care Med. 29, 385-391 (2001).

11 Tomaselli, F., Maier, A., Matzi, V., Smolle-Jüttner, F. M. \& Dittrich, P. Penetration of meropenem into pneumonic human lung tissue as measuread by in vivo microdialysis. Antimicrob. Agents Chemother. 48, 2228-2232 (2004).

12 Sklirladze, K. et al. Impared target site penetration of vancomycin in diabetic patients following cardiac surgery. Antimicrob. Agents Chemother. 50, 1372-1375 (2006).

13 Nolting, A., Dalla Costa, T., Rand, K. H. \& Derendorf, H. Pharmacokinetic-pharmacodynamic modeling of the antibiotic effect of piperacillin in vitro. Pharm Res. 13, 91-96 (1996).

14 Dalla Costa, T., Nolting, A., Rand, K. \& Derendorf, H. Pharmacokinetic-Pharmacodynamic Modeling of the In Vitro Antiinfective Effect of Piperacillin-Tazobactam Combinations. Int. J.Clin. Pharmacol Ther. 35, 426-433 (1997).
15 Bonapace, C. R., Friedrich, L. V. \& Bosso, J. A. Determination of antibiotic effect in an in vitro pharmacodynamic model: comparison with an established animal model of infection. Antimicrob. Agents Chem. 46, 3574-3579 (2002).

16 Dudley, M. N. \& Griffith, D. Animal models of infection for the study of antibiotic pharmacodynamics. in Antimicrobial Pharmacodynamics in Theory and Clinical Practice. (eds Nightingale, C., Murakawa, T., Ambrose, P. G.) 1st edn, 67-97 (MacGraw Hill, New York, USA, 2002).

17 Gloede, J., Scheerans, C., Derendorf, H. \& Kloft, C. In vitro pharmacodynamic models to determine the effect of antibacterial drugs. J. Antimicrob. Chemother. 65, 186-201 (2010).

18 FDA- guidance for Industry: Bioanalytical Method Validation, (http:www.fda.gov/cder/ guidance/index.htm), 2001.

19 Vogelman, B., Gudmundsson, S. \& Legget, J. In vivo postantibiotic effect in a thigh infection in neutropenic mice. J. Infect. Dis. 146, 423-428 (1988).

20 Gibaldi, M. \& Perrier, D. Pharmacokinetics, Marcel Dekker, New York, (1982).

21 Smith, H. What happens to bacterial pathogens in vivo? Trends Microbiol. 6, 239-243 (1998).

22 Bakker-Woudenberg, I. A., Ten Kate, M. T., Goessens, W. H. \& Mouton, J. W. Effect of Treatment Duration on Pharmacokinetic/Pharmacodynamic Indices Correlating with Therapeutic Efficacy of Ceftazidime in Experimental Klebsiella pneumoniae Lung Infection. Antimicrob. Agents Chemother. 50, 2919-2925 (2006).

23 Brunner, M., Derendorf, H. \& Muller, M. Microdialysis for in vivo pharmacokinetic/ pharmacodynamic characterization of anti-infective drug. Curr. Opin. Pharmacol. 5, 495-499 (2005).

24 Perry, C. M. \& Markham, A Piperacillin/tazobactam: an updated review of its use in the treatment of bacterial infections. Drugs 57, 805-843 (1999).

25 Turnidge, J. D. The pharmacodynamics of $\beta$-lactams. Clin Infect Dis 27, 10-22 (1998).

26 Craig, W. Pharmacodynamics of Antimicrobial: general concepts and applications. in Antimicrobial Pharmacodynamics in Theory and Clinical Practice. (eds Nightingale, C., Murakawa, T., Ambrose, P. G.) 1st edn (MacGraw Hill, New York, USA, 2002). 